\title{
THE CURRENT STATE AND TRENDS OF THE DEVELOPMENT OF DIGITAL TELE-RADIO BROADCASTING SYSTEMS IN THE WORLD
}

\author{
Virgilio Mateus Joao dos Santos, \\ Ministry of Telecommunications, Information Technology and Social Communication, Luanda, Angola, \\ svirgilio5@gmail.com
}

\begin{abstract}
The object of the research is to make an analysis of the current state of the digital tele-broadcasting systems in the world and the transition trends from analogue to digital systems recommended by the International Telecommunication Union (ITU-R) for use in this area are considered. Therefore, the current trend of global transition to digital tele-broadcasting is due not only to the lack of a frequency resource, but also to society's growing demands for up-to-date information, the need to introduce common global standards and systems for broadcasting systems. expansion of digital tele-broadcasting in the context of globalization, as well as the presence of this transmission technology. In this work, he is dedicated to considering the sustainable development trends of digital satellite broadcasting in the world in the phase of migration from analog to digital technologies in this area. In the final part, the results obtained based on the research and analysis made in recommendations and in the ITU-R database are presented.
\end{abstract}

KEYWORDS: tele-radio, terrestrial, broadcasting, digital, systems, frequencies, transmitters, transition, satellite, broadcasting, International Telecommunication Union

Information about author

Virgilio Mateus Joao dos Santos, PhD., Deputy responsible for the Department of Space Sciences and Applied Research. National Space Program Management Office4 Ministry of Telecommunications, Information Technology and Social Communication, Angola-Luanda 
The Radiodifusion and digital television use the internet and $4 \mathrm{G}$ technology through cable, satellite, and mobile communications systems to keep the population informed. Despite the rapid development of 5G technology. In addition, there is a transition to active digital broadcasting systems and recommended by the International Telecommunication Union ITU-R for application in this area. This is mainly due to the additional benefits offered by digital television technologies and their expansion in the world. These benefits include $[1,13]$ :

- the ability to create single frequency networks, which significantly saves the radio frequency resource, and increases the efficiency of the use of the radio spectrum;

- improve image and sound quality, the ability to switch to surround, stereo and multichannel broadcasting;

- guarantee the protection of broadcast programs and other information against unauthorized access, which makes it possible to create paid broadcast programs;

- creation of interactive systems of tele-broadcasting, using which, the viewer and/or listener has the opportunity to work on the broadcast program, to request programs of interest to him at a time convenient for him;

- improve the quality and number of programs broadcast in the long wave (LF), medium (MF) short (HF) bands, with significant energy savings by radio devices and transmitters;

- the possibility of receiving high-quality mobile digital radio broadcasting programs, both in megacities and in places with compact populations, and in remote and inaccessible territories with low population density;

- the possibility of transmitting alerts to the population, governmental organizations, special services, stateowned companies, and in emergency situations.

Therefore, the current trend of global transition to digital tele-broadcasting is due not only to the lack of a frequency resource, but also to society's growing demands for up to date information, the need to introduce common global standards and systems for broadcast systems. expansion of digital tele-broadcasting in the context of globalization, as well as the presence of this transmission technology. This work is dedicated to considering the sustainable development trends of digital satellite broadcasting in the world in the phase of migration from analog to digital technologies in this area.

The development of an analog television program eventually led to the spread of three main standards in the world for color television: NTSC, SECAM, PAL [1]. Television in these formats is still watched in many countries, almost half a century after its creation.

The NTSC system (National Television System Committee) is used in North and Central America, in several countries in the eastern part of South America, as well as in Japan, South Korea and in several countries in the Southeast Asian [1]. The SECAM system (Séquentiel Couleur á Mémore - Sequential Color With Memory) is used in Russia, the countries of Eastern Europe and the Commonwealth of Independent States (CIS), France, most countries in North Africa and Southeast Asia [1, 2].
The PAL (Phase Alternate Line) system is used in most western and northern European countries, India, China, Australia, Brazil, Argentina, Angola, and other countries [1].

Among the digital terrestrial television transmission systems recommended by ITU-R for application in this area, two from the DVB (Digital Video Transmission) family are particularly noteworthy: DVB-T, DVB-T2 (where $\mathrm{T}$ is Terrestrial), and for the satellite system two are also worth noting: DVB-S (Digital Video Transmission via Satellite), DVB-S2. The DVB-T2 system (figure 1 ) is perhaps one of the most common Digital TV systems recommended by ITU-R for use in the VHF (Very high frequencies, $30 \ldots 300 \mathrm{MHz}$ ) and UHF (Ultra-High Frequency) bands 300 ... $3000 \mathrm{MHz}$ ). The European Telecommunications Standards Institute DVB-T standard emerged in $1996[1,3,4]$. Figure 1 . We show the number of countries and their respective digital broadcasting systems.

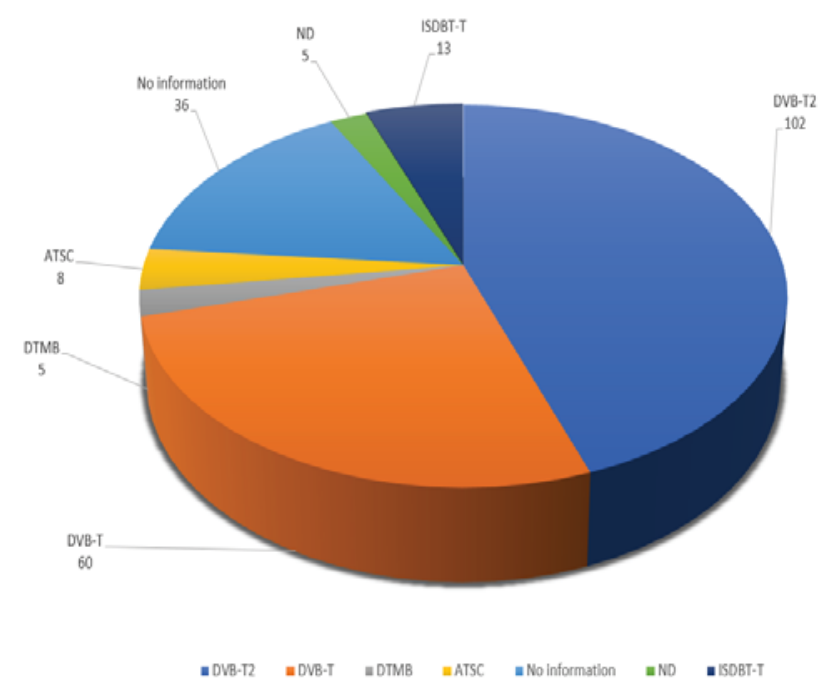

Figure 1. Number of countries and respective digital broadcasting systems

In February 2006 (within the scope of the DVB consortium), the creation of a study committee for this mission was established. This committee had to assess the potential of various digital television technologies and start to develop an improved standard, called DVB-T2, which also implements several business requirements:

- the bility to receive programs on existing simple home antennas;

- the transition to a new standard should not require a change in the transmission network infrastructure;

- an increase of at least 30 to $50 \%$ in productivity compared to the DVB-T system under identical transmission conditions;

- increase the flexibility of using the radio band's frequency band, and the possibility of diversification;

- the presence of a mechanism to reduce the peak power of the transmitted signal to the average value and several other less important requirements. 
The above recommendations were implemented in the development of the DVB-T2 standard in 2010. The decision to implement the DVB-T2 standard was taken by the administrations of Austria, Great Britain, Germany, Denmark, India, Spain, Italy, Kazakhstan, Slovakia, Ukraine, Finland, Czech Republic, Sweden, South Africa, Russia, and many other countries in transition. In addition, in several countries in the world, the transition to digital TV has already been completed $[1,25]$. In some countries, it did not even begin as (Bangladesh, Belize, Central African Republic, Eritrea, Jamaica) as shown in Figure 2.

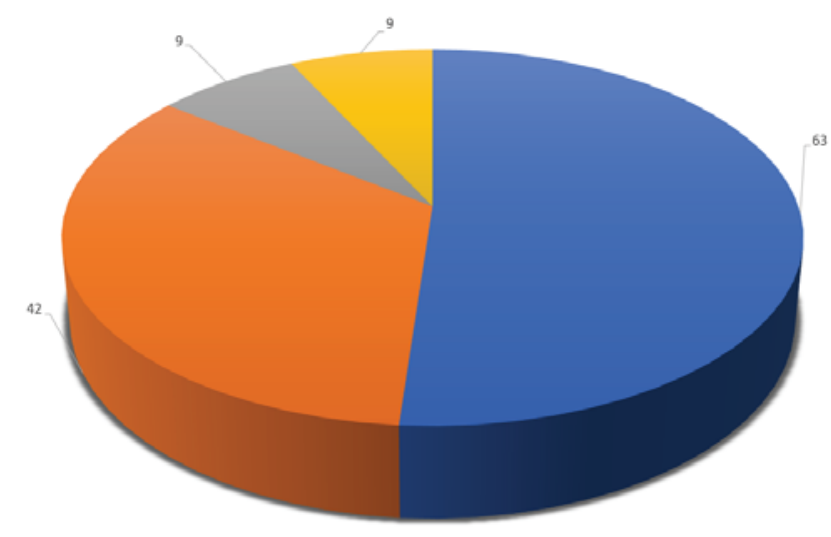

Figure. 2. Number of countries and their status for transition from the Digital TV system

We emphasize once again (figures 1 and 2) that the DVB-T2 system, which currently has the best characteristics, is the most used among the countries that have already opted for the digital television system (figure 1). The transition from analogue to digital television systems, established by the ITU-R Regional Radiocommunication Conference in Geneva in 2006 (RRC-06), was due to be completed in June 2015 [4]. However, due to several reasons (organizational, economic, and technical), this period was later postponed to 2020 [4].

The observed decrease in the cost of equipment for digital television networks of the DVB-T2 standard will allow that by the year 2030, highly efficient systems will be created for the delivery of digital content to users. At the same time, the limited volume spectrum is released due to the migration from analog to digital television for other types of use, mainly for mobile communication systems. We can say that in the world there is a process of transition to digital TV, which has not yet been fully concluded.

As for digital broadcasting systems, the situation is much more complicated: in many countries there is a clear delay in terms of switching to the "digit" in the very high frequency range (VHF $30 \ldots 300 \mathrm{MHz}$ ), intended (according to with the ITU-R recommendations) mainly for the use of high quality stereo broadcasting systems. Recommendations ITU-R.BS.1114-6 [22] and ITUR.BS1660-6 (08/2012) [23] ITU-R present the construction resources, technical characteristics, and network planning of the following terrestrial digital broadcasting systems:

- T-DAB (Digital Audio Broadcasting), digital radio system in a $174 . .240 \mathrm{MHz}$ frequency band, VHF III [10];

- ISDB-T (Integrated Services Digital Broadcasting Terrestrial), is a system recommended for television channels with a width of 6,7 or $8 \mathrm{MHz}$ for the transmission of sound programs, a segment is allocated as a fourteenth of the frequency range of the television channel, the frequency range of that segment is $429 \mathrm{kHz}(6 / 14)$, $500 \mathrm{kHz}$ (7/14), $571 \mathrm{kHz}(8 / 14)$ [29];

- DRM + (Digital Radio Mondiale), recommended by ITU-R for use in the LF $(30 \ldots 300 \mathrm{kHz}), \quad \mathrm{MF}$ $(300 \ldots 3000 \mathrm{kHz}), \quad \mathrm{HF} \quad(3 \ldots 30 \mathrm{MHz})$ and VHF $(30 \ldots 300 \mathrm{MHz}$ ) bands where bands of specific frequencies are allocated for other transmission purposes [8];

- IBOC HD Radio FM (In Band On Channel), recommended by the ITU-R for use in the VHF band [9];

- RAVIS [1, 24], is a Russian audiovisual information system in real time, recommended by the ITU-R for use in the VHF band. Note that the IBOC HD Radio FM and IBOC HD Radio AM technologies are combined under one standard. The same observation applies to DRM and DRM + systems. Of the above-mentioned systems, Digital broadcasting, only two are the most universal, recommended by ITU-R for use in all frequency bands allocated for transmission (LF, MF, HF, VHF bands). These are the DRM and IBOC HD radio systems.

From the data in table 2, it follows that the DAB system is currently the most widely used [6].

Initially, the Digital Audio Broadcasting (DAB) system was positioned by the developers only as a digital broadcasting system, designed to transmit quality sound programs, different information related only to digital data.

The DAB (Digital Sound Broadcasting) system is a system for use in megacities, as well as in areas with high population density, where the construction of a single frequency network is beneficial. However, this does not exclude its use either at the regional level, or simply at radio stations operating separately, which is also provided by the standard. Later, more efficient digital audio data compression algorithms were developed and standardized $[5,16,17,18,19]$. They were added to the new second version of the standard, called DAB + , which appeared in 2006 [5]. In particular, compression algorithms were added in the HE-AAC v.2 (High Efficiency- Advanced Audio Coding) encoder of the MPEG-4 standard (Moving Picture Experts Group). Moving Images) ISO/IEC 14496-3 [18] (International Organization for StandardizationInternational Organization for Standardization and International Electrotechnical Commission-International Electrotechnical Commission) and MPEG D (Group of Experts in Moving Images) Surround [19]. The ability to use the MPEG-1 ISO/IEC 11172-3 Layer II compression algorithm remained in this version of the standard for the $\mathrm{DAB}+$ system.

The DAB + (Digital Sound Radio) system is a much more flexible technology when used in small towns, it is possible to receive mobile data in a simple whip antenna 
from a wide variety of multimedia information, including mobile television. Note that the subsequent processing of the digital data of the subchannels in the $\mathrm{DAB}+$ system has not changed compared to the DAB system. In 2009, there was an addition to the DAB + system, dedicated to the transmission of video information (video services), which transforms it into a complete multimedia system focused on mobile reception and television transmission $[6,14,20]$.

According to the ITU-R recommendations, regular transmission of DAB / DMB family systems is carried out in 41 countries, and experimental transmission in 18 other countries. Since 2005, the T-DMB system started broadcasting in Seoul (South Korea). At the beginning of 2006, there were already 18 projects in the world to introduce DMB technology based on the terrestrial transmission infrastructure of the existing T-DAB system. In Europe, the main projects were launched in Germany, France, Norway, the Netherlands, Finland, England and Italy
$[14,15]$. The leader in this process is Germany, where in June 2006 there were already 39 T-DMB transmitters operating in 12 cities based on the use of transport mechanisms in the DAB + system.

In 2016, the most recent version of the standard for the DAB system appeared [10]. The specification [19] transforms the DAB / DAB + system in terms of its characteristics into multimedia $\mathrm{A}$ systems (also known as $\mathrm{T}$ DMB), [20,12,21]. On a $1.54 \mathrm{MHz}$ radio channel using transport mechanisms, DAB systems can be transmitted simultaneously: ity;

- sev ral sound programs with different levels of qual-

- several television programs with monophonic or stereo accompaniment;

$-\mathrm{v}$ rious data, relevant information for entrepreneurs, fixed and mobile images, text and graphic information, etc.

Table 1

\begin{tabular}{|c|c|c|}
\hline Technical characteristics & $\begin{array}{c}\text { DVB-S2 System } \\
\text { ETSI EN } 302 \text { 307-2 V1.2.1 (2020-08) } \\
{[30,31]}\end{array}$ & $\begin{array}{c}\text { DVB-S System } \\
\text { ETSI EN } 302307 \text { V1.4.1 (2014-07) }\end{array}$ \\
\hline 1. D a input & $\begin{array}{l}\text { Multiple transport flow and generic } \\
\text { encapsulation (GSE) }\end{array}$ & A single transport streams (MPEG-TS) \\
\hline 2. Mod & $\begin{array}{l}\text { Variable encoding. Coding adapted to } \\
\text { modulation }\end{array}$ & Constant and modulated coding \\
\hline 3. Er $\mathrm{r}$ correction (FEC) & $\begin{array}{l}\mathrm{LDPC}+\mathrm{BCH} 1 / 4,1 / 3,2 / 5,3 / 4,4 / 5,5 / 6, \\
6 / 7,8 / 9,9 / 10\end{array}$ & Reed - Solomon (RS) $1 / 2,2 / 3,3 / 4,5 / 6,7 / 8$ \\
\hline 4. Modulati & QPSK, 8PSK, 16APSK, 32APSK & Single carrier QPSK \\
\hline 7. Satéllite EI $(\mathrm{dBW})$ & 53.7 & 51 \\
\hline 9. Modulati and coding & QPSK 7/8 & QPSK 2/3 \\
\hline 10. en speed & $30,9(a=0,35)$ & $27,5(a=0,35)$ \\
\hline 11. C $\quad(27,5 \mathrm{MHz})$ & 7,8 & 7,8 \\
\hline 12. ansfer fee per (Mbit/s) & $58,8(+32 \%)$ & 33,8 \\
\hline 13. № de channels SBTV & $\begin{array}{l}13 \text { MPEG - } 2 \text { AVC } \\
26 \text { MPEG - } 4 \text { AVC }\end{array}$ & $\begin{array}{l}10 \mathrm{MPEG}-2 \mathrm{AVC} \\
20 \mathrm{MPEG}-4 \text { AVC }\end{array}$ \\
\hline 14. № de channels HDTV & $\begin{array}{l}3 \text { MPEG - } 2 \text { AVC } \\
6 \text { MPEG - } 4 \text { AVC }\end{array}$ & $\begin{array}{l}2 \mathrm{MPEG}-2 \mathrm{AVC} \\
5 \mathrm{MPEG}-4 \text { AVC }\end{array}$ \\
\hline
\end{tabular}

Table 2

\begin{tabular}{|c|c|c|c|c|}
\hline & System name & \multicolumn{2}{|c|}{ Tele-broadcasting } & Starting year \\
\hline \multirow{3}{*}{ Europe } & DVB-S & & Satellite & 1998 \\
\cline { 2 - 5 } & DVB-S2x & TV & Satellite & 2006 \\
\cline { 2 - 5 } & DAB & Audio & Terrestrial/satellite & 2003 \\
\cline { 2 - 5 } & DRM & Au & Satellite & 2003 \\
\hline \multirow{3}{*}{ USA } & IBOC & Audio & Serrestrial & 2001 \\
\cline { 2 - 5 } & Sirius & Aud & Satellite & 2001 \\
\cline { 2 - 5 } & XM & Satellite & 2000 \\
\hline \multirow{3}{*}{ Japan } & ISDB-S & Audio & Satellite & 2003 \\
\cline { 2 - 5 }
\end{tabular}


Table 3

\begin{tabular}{|c|c|c|c|c|}
\hline \multirow{2}{*}{$\begin{array}{c}\text { Condition } \\
\text { (Status) }\end{array}$} & \multicolumn{4}{|c|}{ Digital Broadcasting System Name [32] } \\
\hline & $\mathrm{DAB} / \mathrm{DAB}+$ & DRM/DRM+ & IBOC HD RADIO FM & ISDB-T \\
\hline \multirow{22}{*}{ 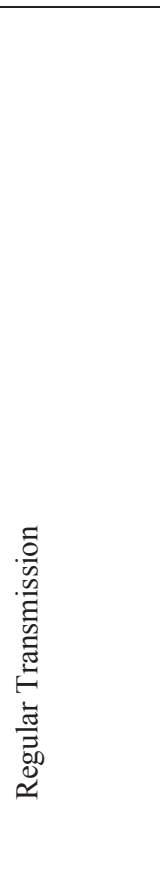 } & Australia & Tunisia & United States of America & Argentina \\
\hline & Belgium & Malaysia & Argentina & Brazil \\
\hline & Czech republic & Hungary & Mexico & Bolivia \\
\hline & Denmark & India & Canada & Botswana \\
\hline & France & Canada & Czech Rep. & Venezuela \\
\hline & Germany & Ecuador & Colombia & Costa Rica \\
\hline & Hong Kong & Mongolia & Jamaica & Peru \\
\hline & Ireland & Finland & - & Paraguay \\
\hline & Italy & Japan & - & Japan \\
\hline & Kuwait & New Zealand & - & \\
\hline & Malta & Corea & - & - \\
\hline & Monaco & Rússian & - & - \\
\hline & Netherlands & México & - & - \\
\hline & Norway & - & - & - \\
\hline & Poland & - & - & - \\
\hline & Slovenia & - & - & - \\
\hline & South Korea & - & - & - \\
\hline & Spain & - & - & - \\
\hline & Sweden & - & - & - \\
\hline & Switzerland & - & - & - \\
\hline & United Kingdom & - & - & - \\
\hline & - & - & - & - \\
\hline \multirow{23}{*}{ 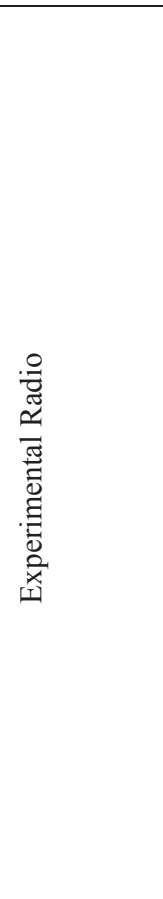 } & Austria & Brasilia & China & Uruguay \\
\hline & Bahrain & France & Poland & Chile \\
\hline & Brunei Darussalam & Croatia & savior & Nicaragua \\
\hline & China & Germania & France & Honduras \\
\hline & Taipei & Pakistan & Germany & savior \\
\hline & Italy (Rome) & Italy & Indonesia & Guatemala \\
\hline & Hungary & Romania & Philippines & Philippines \\
\hline & Indonesia & Nigeria & Puerto Rico & Sri Lanka \\
\hline & Israel & Beautiful Russia & Panama & Moldova \\
\hline & Latvia & - & Dominican Rep. & Ecuador \\
\hline & Malaysia & - & - & Angola \\
\hline & Mongolia & - & - & - \\
\hline & Myanika & - & - & - \\
\hline & New Zealand & - & - & - \\
\hline & Slovakia & - & - & - \\
\hline & South Africa & - & - & - \\
\hline & Thailand & - & - & - \\
\hline & Tunisia & - & - & - \\
\hline & Turkey & - & - & - \\
\hline & Ukraine & - & - & - \\
\hline & United Arab Emirates & - & - & - \\
\hline & Estonia & & & \\
\hline & & - & - & - \\
\hline \multirow{7}{*}{ 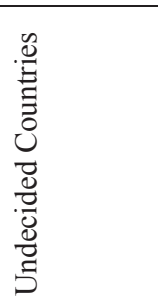 } & Lithuania & Mozambique & - & - \\
\hline & Russian Federation & Tanzania & - & - \\
\hline & Serbia & Zambia & - & - \\
\hline & Singapore & & - & - \\
\hline & Sri Lanka & - & - & - \\
\hline & Vietnam & - & - & - \\
\hline & & & & \\
\hline
\end{tabular}


The DRM (Radio Digital Mondiale) system is a multifunctional digital transmission system, which was first standardized by the European Telecommunications Standards Institute (ESTI) in 2001 [8]. Originally, he intended to operate in the long wave (LF), medium (MF) and short (HF) transmission bands, that is, in the frequency sections of up to $30 \mathrm{MHz}$ allocated by the ITU-R for audio transmission.

In 2009, a new version of this standard was published, in which the operating frequency range was expanded to a frequency of $240 \mathrm{MHz}$ [14].

In this version of the standard, operation mode E, version of the system itself, is added, when operating in this mode, in a series of publications that received the name of $\mathrm{DRM}+$. The latest version of this standard was published in January 2014 [1,14, 27, 28, 29].

Unfortunately, although there is no mass production of receivers of this format, the distribution of this system in the world is much slower, but still the number of countries focusing on its use is quite large (Table 3). For this reason, this system is recommended for countries with large territory and low population density.

Table 3. Distribution of digital transmission systems via satellite recommended by the ITU for application in this area $[30,31]$.

As for the countries of North and South America, the American IBOC HD Radio system is spreading in some countries (Table 2).

\section{Conclusion}

1. In almost all documents and recommendations of the International Telecommunications Union for application in television and satellite broadcasting, digital systems have some transversal characteristics common in the processing and transmission of digital image and sound data, among which must be attributed: the compression of digital data, the permissible noise, the encoding of the audio and video-frame level, randomness of the digital data, which is necessary for a more balanced distribution of the signal energy in a frequency range of the radio channel, channels coding with different levels of protection of individual parts of digital streams, temporarily alternating digital data, alternating a cell modulation frequency during OFDM-character formation; multiple frequencies with OFDM or COFDM modulation, but with different configurations. It is the difference of these small details that ultimately determine their efficiency, quality, and the choice of countries for application in their respective territories.

2. Different publications by individual authors have been analyzed, reports and ITU-R recommendations show that the world is currently in constant transition from digital tele-broadcasting systems under the responsibility of two digital technology platforms for these systems, with emphasis on Europe (the DVB-T, DVB-T2, DVB-S, DVB-S2 system). Currently 102 countries in the world have adopted the European DVB-T2 standard.
3. The promotion of DRM and ISDB-T systems, despite their high efficiency, quality is slow enough, which apparently is the lack of mass production, the high cost of receivers of a given format. With the pandemic moment we are experiencing, the technological industries stop producing equipment on a large scale, so the process has become slower.

\section{Referencies}

1. V.P. Dvorkovich, A.V. Dvorkovich. Digital video information systems (theory and practice). Moscow: Tenchnosfera, $2012.1008 \mathrm{p}$.

2. Rep.ITU-R.BT.2043 (2004) Analogue television systems currently in use throughout the world.

3. ETSI EN 302755 V1.3.1 (2012-04). Digital Audio Broadcasting (DVB); frame structure channel coding and modulation for a second-generation digital terrestrial television broadcasting system (DVB-T2).

4. ITU-NEWS. Special report on the Switchover. - №2.2015. URL:itu.int/bibar/ITUJournal/DocLibrary/ITU011-201502-en.pdf (Date of access to resource 16.08.2020)

5. ETSI ETS 300401. Radio Broadcasting System; Digital Audio Broadcasting (DAB) Tomobile, portable and fixed receivers, May 1997.

6. L.N. Katsnelson. Sound and multimedia digital radio broadcasting systems: scientific and technical edition. St. Petersburg: Link, 2011. 348 p.

7. ETSI EN 300401 V1.4.1 (2006-01). Radio Broadcasting Systems; Digital Audio Broadcasting (DAB) mobile, portable and fixed receivers.

8. ETSI ES 201980 V3.2.1 (2012-06). Digital Radio Mondiale (DRM) system Specification.

9. National radio systems committee, NRSC-5-C, Inband/on-channel Digital Radio Broadcasting Standard September, 2011.

10. ETSI EN 300401 V2.1.1 (2016-10). Radio Broadcasting System; Digital Audio Broadcasting to mobile, portable and fixed receivers.

11. ETSI TS 102428 V1.2.1 (2009-04). Digital Audio Broadcasting (DAB); DMB video service; User application specification

12. ETSI TS 102427 V.1.1.1 (2005-07) Digital Audio Broadcasting (DAB); Data Broadcasting - MPEG-2 TS streaming.

13. A.V. Smirnov, A.E. Peskin. Digital television (from theory to practice). Moscow: Tenchnosfera, 2011.352 p.

14. L. N. Katsnelson. Digital radio broadcasting systems $\mathrm{DAB}, \mathrm{DAB}+$, DMB. State of the art. Broadcasting. Television and radio broadcasting. 2015. No. 1. P. 25.

15. ISO/IEC 13818-3:1998. Information technology - Generic coding of moving pictures and associated audio information - Part 3: Audio.

16. International Standard ISO/IEC 13818-7. Information technology-Generic coding of pictures and associated audio information. Part 7: Advanced Audio Coding (AAC), 1997 (E).

17. ISO/IEC FCD 14496-3 Subpart 1. Information Technology-Very Lov Bitrate Audio-Visual Coding. Part 3: Audio, 1998-05-10 (ISO/JTC 1/SC 29, N2203).

18. ISO/IEC 23003-1:2007, "Information Technology MPEG Audio Technologies - Part 1: MPEG Surround," International Standards Organization, Geneva, Switzerland (2007). 
19. ETSI TS 102428 V1.2.1 (2009-04). Digital Audio Broadcasting (DAB); DMB video service; User application specification.

20. Recommendation ITU-R (02/2014). Broadcasting for mobile portable receiver reception of multimedia and data applications 21. Report ITU-R BT.2049-7 (02/2016). Broadcasting of multimedia and data applications for mobile reception

22. Recommendation.ITU-RBS.1114-11 (06-2019) Systems for digital sound broadcasting to vehicular, portable and fixed receivers in the frequency range $30-3000 \mathrm{MHz}$.

23. Recommendation.ITU-R BS.1660-08 (06/2019). Technical basis for planning of terrestrial digital sound broadcasting in the VHF band.

24. GOST R 54309-2011. Real Time Audiovisual Information System (RAVIS). Processes of formation of a frame structure, channel coding and modulation for a digital terrestrial narrowband broadcasting system in the VHF range. Technical conditions. Moscow: Standartinform, 2012. 39 p.

25. Report. ITU-R BT.2140-12 (07/2019) Transition from analogue to digital terrestrial broadcasting.

26. Material taken from the website of the International Telecommunication Union. URL:https://www.itu.int/en/ITU-
D/Spectrum-Broadcasting/DSO/Pages/Countries.aspx( Date of access to resource 17.08.2020)

27. Material taken from the DRM official website, URL: http://www.drm.org/about-us/drm-members/(Date of access to resource 17.08.2020).

28. Material taken from DiBerg's official website, URL: http://www.dibeg.org/index.html (Date of access to resource 17.08.2020).

29. ETSI EN 300744 V1.6.1 (2009-01) Digital Video Broadcasting (DVB); Framing structure, channel coding and modulation for digital terrestrial television

30. ETSI EN 302307 V1.2.1 (2009-08) Digital Video Broadcasting (DVB); Second generation framing structure, channel and modulation systems for Broadcasting, Interactive Services, News Gathering and other broadband satellite applications (DVS-S2)

31. ITU-News Magazine. Evolving satellite communications. No. 2, 2019.

32. Santos V. Kovalgin.Yu.A. Currente state and development trends of digital television and radio broadcasting the in world. Information and space. 2017. No. 2. P. 11-24. 